\title{
Assessment of effectiveness of nature reserves on the Tibetan Plateau based on net primary production and the large sample comparison method
}

\author{
ZHANG Yili ${ }^{1,2}$, HU Zhongjun ${ }^{1,3},{ }^{*}$ QI Wei ${ }^{1,3}$, WU Xue ${ }^{1,3}$, BAI Wanqi ${ }^{1}$, LI Lanhui ${ }^{1,3}$, \\ DING Mingjun ${ }^{1,4}$, LIU Linshan ${ }^{1}$, WANG Zhaofeng ${ }^{1}$, ZHENG Du ${ }^{1}$ \\ 1. Key Laboratory of Land Surface Pattern and Simulation, Institute of Geographic Sciences and Natural Re- \\ sources Research, CAS, Beijing 100101, China; \\ 2. CAS Center for Excellence in Tibetan Plateau Earth Sciences, Beijing 100101, China; \\ 3. University of Chinese Academy of Sciences, Beijing 100049, China; \\ 4. Key Laboratory of Poyang Lake Wetland and Watershed Research, Ministry of Education, Jiangxi Normal \\ University, Nanchang 330022, China
}

\begin{abstract}
Twenty-one typical coupled large samples were chosen from areas within and surrounding nature reserves on the Tibetan Plateau using the large sample comparison method (LSCM). To evaluate the effectiveness of the nature reserves in protecting the ecological environment, the alpine grassland net primary production (NPP) of these coupled samples were compared and the differences between them before and after their establishment as protected areas were analyzed. The results showed that: (1) With respect to the alpine grassland NPP, the ecological and environmental conditions of most nature reserves were more fragile than those of the surrounding areas and also lower than the average values for the Tibetan Plateau. (2) Of the 11 typical nature reserves selected, the positive trend in the NPP for Manzetang was the most significant, whereas there was no obvious trend in Taxkorgan. With the exception of Selincuo, the annual NPP growth rate in the nature reserves covered by alpine meadow and wetland was higher than that in nature reserves consisting of alpine steppe and alpine desert. (3) There were notable findings in 21 typical coupled samples: (a) After the establishment of the nature reserves, the annual rate of increase in the NPP in $76 \%$ of samples inside nature reserves and $82 \%$ of samples inside national nature reserves was higher than that of the corresponding samples outside nature reserves. (b) The effectiveness of ecological protection of the Mid-Kunlun, Changshagongma, Zoige and Selincuo (Selin $\mathrm{Co}$ ) nature reserves was significant; the effectiveness of protection was relatively sig-
\end{abstract}

Received: 2015-05-22 Accepted: 2015-09-21

Foundation: The Strategic Priority Research Program of the Chinese Academy of Sciences, No.XDB03030500; National Key Technology Research and Development Program, No.2013BAC04B02; Key Foundation Project of Basic Work of the Ministry of Science and Technology of China, No.2012FY111400; National Natural Science Foundation of China, No.41171080, No.41201095

Author: Zhang Yili (1962-), Professor, specialized in physical geography and biogeography.

E-mail: zhangyl@igsnrr.ac.cn

*Corresponding author: Qi Wei (1987-), PhD, E-mail: qiw@igsnrr.ac.cn

This paper has been published in Chinese and revised partially. 
nificant in most parts of the Sanjiangyuan and Qiangtang nature reserves, whereas in south-east Manzetang and north Taxkorgan the protection effectiveness was not obvious. (c) The ecological protection effectiveness was significant in nature reserves consisting of alpine meadow, but was weak in nature reserves covered by alpine steppe. This study also shows that the advantage of large sample comparison method in evaluating regional ecology change. Careful design of the samples used, to ensure comparability between the samples, is crucial to the success of this LSCM.

Keywords: nature reserves; protection effectiveness; large sample comparison method; net primary production; Tibetan Plateau

\section{Introduction}

The world's first nature reserve-Yellowstone National Park in the USA-was created in 1872. One hundred and forty years of practice has proved that nature reserves are the best way to protect biodiversity; they are also effective in constructing ecosystems and maintaining regional ecological security (Ma, 1992; Wang et al., 2003; Cui, 2004; Chen et al., 2010). The first nature reserve in China was the Dinghushan Nature Reserve, which was established in 1956. The State Council of China promulgated the Regulations of the People's Republic of China on Nature Reserves in September 1994, outlining the creation of nature reserves, the regulations for their management and legal responsibilities. After these regulations had been published, the development of nature reserves in China entered a rapid and orderly phase (Chen, 2012).

The Tibetan Plateau (TP) is known as the "Roof of the World" and the "Third Pole of the World" (Zhang et al., 2002). Both its ecology and environment are sensitive and fragile (Sun et al., 2012). In particular, regions to the west of Ali, the central-south part of Naqu, the Sanjiangyuan region and the Three Parallel Rivers Region are areas of key ecological significance (Mittermeier et al., 2011; Nan, 2013; Zhang et al., 2013b). To protect the environment, resources and biodiversity, 155 nature reserves have been created here since 1963, with a total area of approximately $8.22 \times 10^{5} \mathrm{~km}^{2}$, accounting for $32.35 \%$ of the total area of the Tibetan Plateau. Of these nature reserves, national and provincial nature reserves on the Tibetan Plateau account for $54.96 \%$ of the total area of nature reserves (at the national and provincial levels) in China. A system of nature reserves with a reasonable spatial distribution has thus been formed on the Tibetan Plateau, offering a range of types of protection (Zhang et al., 2015). However, to our knowledge, a method for the evaluation of the overall effectiveness of the creation of nature reserves and a standard system of nature reserves have not yet been reported (Zheng et al., 1994; Cui, 2004; Ewers and Rodrigues, 2008; Zheng et al., 2012; Yan et al., 2015). With the exception of individual natural types of reserve or regions, such as wetlands (Victoria et al., 2002; Zheng et al., 2012) and the Sanjiangyuan (Shao et al., 2012; DEPQP et al., 2015), a systematic analysis of the overall effectiveness of protection of the natural reserves on the Tibetan Plateau has not yet been reported.

Many types of evaluation are aimed at particular objectives of protection or types of vegetation or species, such as terrestrial vertebrates (Yan et al., 2015), forest ecosystems (Curran et al., 2004; Andam et al., 2008; Wang et al., 2013), wetland ecosystems (Victoria et al., 2002; Zheng et al., 2012), biodiversity (Bruner et al., 2001; Naughton-Treves et al., 2005), the ecological environment (Shao et al., 2012), the management system used (Stoner 
et al., 2007; Caro et al., 2009; Quan et al., 2009; Chen et al., 2010 ; Leverington et al., 2010; Underwood, 2012), economic value (Naidoo et al., 2006; Yan et al., 2014), social benefit and regional sustainable development (Naughton-Treves et al., 2005; Liu et al., 2008; Radeloff et al., 2010). These studies mainly adopted the delphi method, fuzzy evaluation statistics, the analytic hierarchy process, principal component analysis and other quantitative or qualitative evaluation methods to construct an index system for evaluation. Static evaluation (Zheng et al., 1994) or dynamic assessment (Bruner et al., 2001; Liu et al., 2001; Curran et al., 2004; Mas, 2005; Deng et al., 2010; Shao et al., 2012; Zheng et al., 2012; Yan et al., 2014, 2015) were then used to compare the nature reserves by index scoring, weighted average and temporal comparison methods. However, these methods cannot assess several nature reserves contemporaneously with long time series over large-scale areas.

Net primary production (NPP) is an important indicator of the function of ecosystems. In recent decades, the NPP estimated by remote sensing has been widely used in vegetation ecosystem studies (Melillo et al., 1993; Potter et al., 1993; Running et al., 2004; Shvidenko et al., 2008; Crabtree et al., 2009). Based on remote sensing and observational plant biomass data, Zhang et al. (2014) used the Carnegie-Ames-Stanford Approach model to determine the spatio-temporal variability in the alpine grassland NPP on the Tibetan Plateau since 1982. This enabled the quantitative assessment of the effectiveness of protection of nature reserves on the Tibetan Plateau from the perspective of changes in the ecological system based on long time series data obtained by remote sensing.

Alpine grassland is the dominant vegetation type on the Tibetan Plateau, accounting for about $60 \%$ of its total area (Zhang et al., 2014). For this study, we selected 11 typical nature reserves covered mainly by alpine grassland, including alpine meadows, alpine steppe, wetlands or alpine desert (Figure 1a). We then selected 21 contrasting coupled samples inside and outside the nature reserves (Figure $1 \mathrm{~b}$ ). We analyzed the differences in the alpine grassland NPP between the regions inside and outside the nature reserves before and after their creation to evaluate their effectiveness in protection. This study provides a scientific basis for the ecological management of nature reserves and the formulation of national macroscopic policies.

\section{Data and methods}

\subsection{Data sources}

\section{Spatial data}

Alpine grassland NPP data were taken from Zhang et al. (2014) for the period 1982-2009 at a spatial resolution of $0.05^{\circ}$. This dataset was based on Global Inventory Modeling and Mapping Studies (GIMMS) NDVI and SPOT VEGETATION NDVI data; the CarnegieAmes-Stanford Approach model was used to estimate the results. The process of model calculation and the method for verifying the model results are based on previously published methods (Potter et al., 1993; Crabtree et al., 2009; Zhang et al., 2014). The boundary of the Tibetan Plateau was taken as that defined by Zhang et al. (2002). The boundaries of typical nature reserves were taken from Zhang et al. (2012) and the range of alpine grassland (alpine meadow, alpine steppe, wetland, alpine desert and alpine sparse vegetation) were taken 
from Zhang (2007). To reduce analytical errors and uncertainty, all the spatial data were obtained using the WGS84 coordinate systems and the spatial resolution for raster data was set at $0.05^{\circ}$.

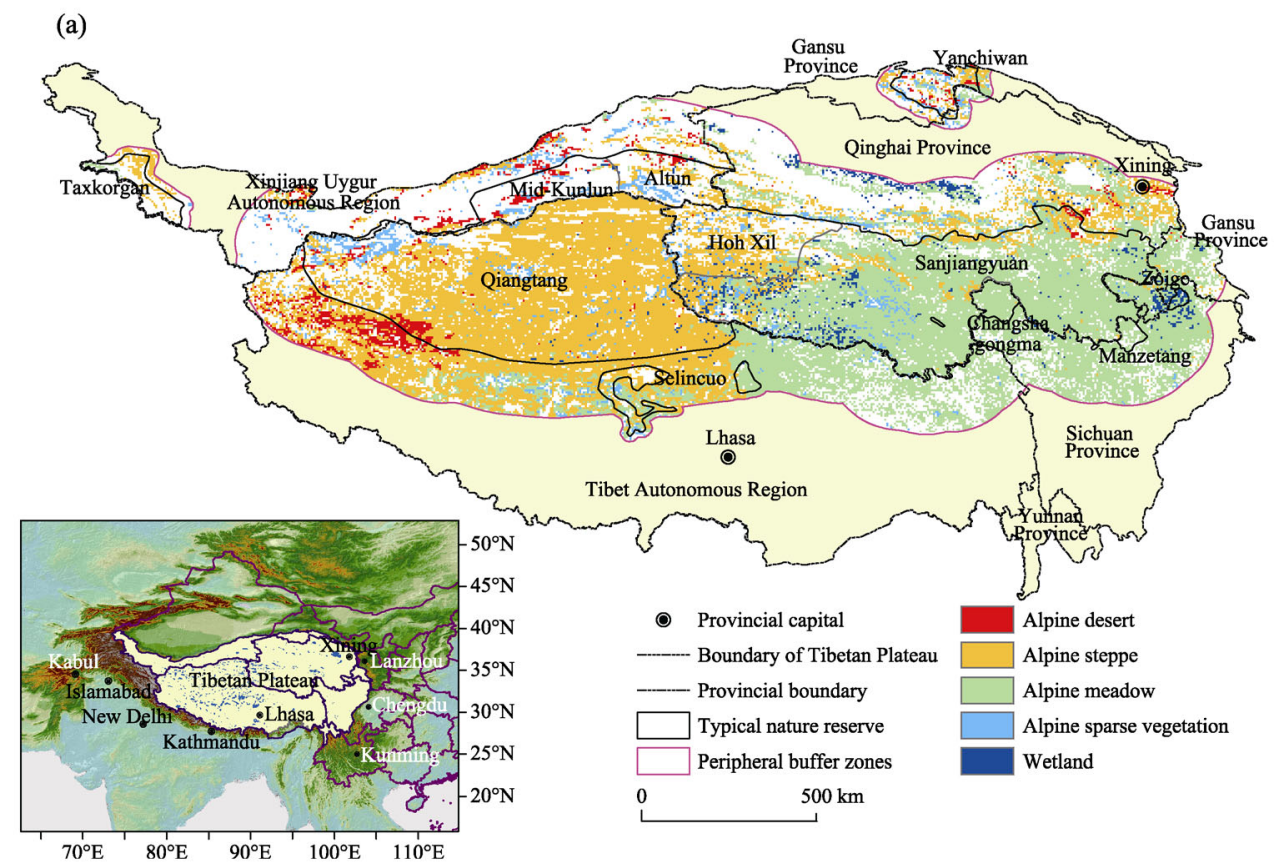

(b)

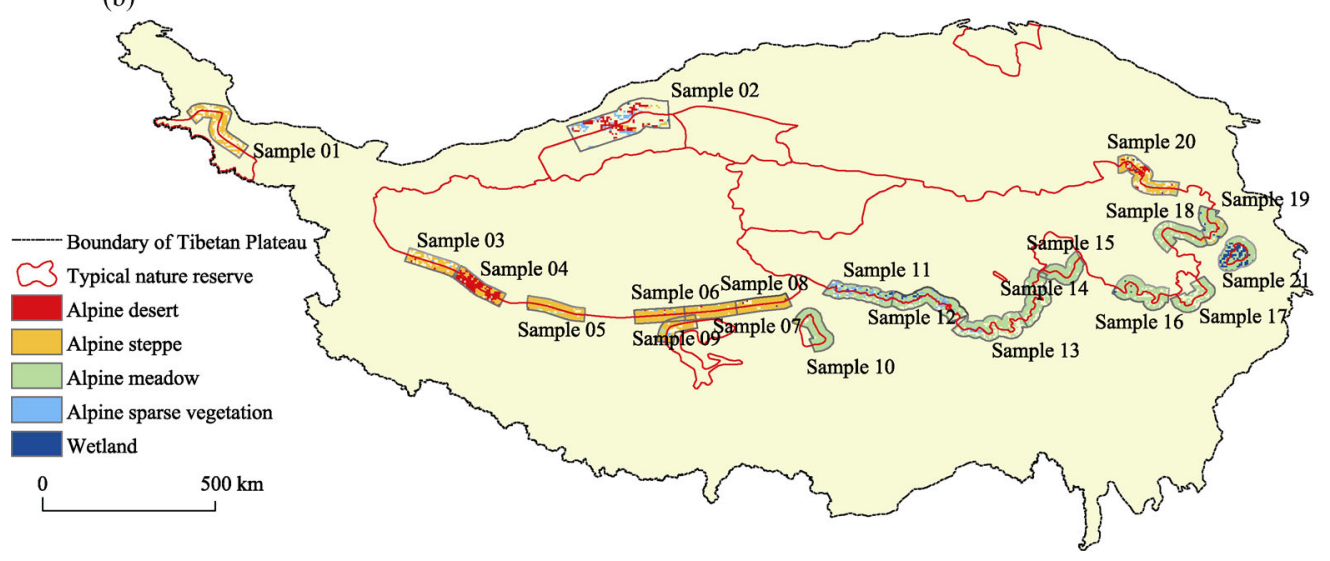

Figure 1 Typical nature reserves and their peripheral buffer zones on the Tibetan Plateau (TP) (a), and 21 typical sample pairs (b)

\section{Nature reserve data}

Information on the nature reserves at the end of 2012 was taken from the list of national nature reserves published by the Department of Nature and Ecology Conservation, Ministry of Environmental Protection of China (http://sts.mep.gov.cn/zrbhq/; Table 1).

\subsection{Methods}

This ecological study considered the principles of vegetation ecology and environment het- 
erogeneity using long time series NPP data, which can indicate the status of ecological systems. ArcGIS 10.1 software was used to conduct the spatial analysis of alpine grassland NPP in typical nature reserves and their peripheral buffer zones. Unlike the delphi and AHP methods, which are usually used to analyze the effectiveness of protection of nature reserves, we used the large sample comparison method (LSCM) and related indexes to study the effectiveness of protection of the reserves.

Table 1 Representative nature reserves on the Tibetan Plateau

\begin{tabular}{lccllc}
\hline \multicolumn{1}{c}{$\begin{array}{c}\text { Name of nature } \\
\text { reserve }\end{array}$} & Area $\left(\mathrm{km}^{2}\right)$ & $\begin{array}{c}\text { Proportion of } \\
\text { alpine grass- } \\
\text { land }(\%)^{*}\end{array}$ & $\begin{array}{c}\text { Type of } \\
\text { protection }\end{array}$ & Level & $\begin{array}{c}\text { Date of } \\
\text { creation }\end{array}$ \\
\hline Qiangtang & $300,000.0$ & 78.31 & Desert ecosystem & National & 09 Jul. 1993 \\
Sanjiangyuan & $150,000.0$ & 84.42 & Inland wetland & National & 23 May 2000 \\
Altun Mountain & $45,000.0$ & 36.69 & Desert ecosystem & National & 01 Jan. 1983 \\
Hoh Xil & $45,000.0$ & 56.13 & Wild animal & National & 08 Oct. 1995 \\
Selincuo & $20,323.8$ & 68.92 & Wild animal & National & 01 Jan. 1993 \\
Yanchiwan & $13,600.0$ & 47.03 & Wild animal & National & 01 Apr. 1982 \\
Changshagongma & $6,698.0$ & 91.07 & Wild animal & National & 08 Dec. 1997 \\
Zoige & $1,665.7$ & 86.25 & Inland wetland & National & 18 Nov. 1994 \\
Mid-Kunlun Mountain & $32,000.0$ & 21.82 & Wild animal & Provincial & 01 Jan. 2001 \\
Taxkorgan & $15,000.0$ & 28.07 & Wild animal & Provincial & 08 May 1984 \\
Manzetang & $3,658.8$ & 64.83 & Inland wetland & Provincial & 08 Jun. 2001 \\
\hline
\end{tabular}

*Calculated data combined with data from Zhang et al. (2007)

We chose representative large samples with equal areas for a comparative analysis of the ecological changes in adjacent zones inside and at the periphery of each nature reserve, for which the ecological and geographical environments were relatively consistent. The selection criteria for the comparative samples were as follows.

(1) The type of ecosystem in each pair of samples (inside the nature reserve and in its peripheral buffer zone) was the same. In addition, the area of the internal and external samples was approximately equal.

(2) There were more than 30 effective pixels in each sample, taking into account the geostatistical requirements. Effective pixels refer to complete pixels $\left(0.05^{\circ} \times 0.05^{\circ}\right)$ with alpine grassland vegetation for which the yearly NPP value can be included in the source data.

(3) There were at least three pairs of comparative samples for all the different kinds of main alpine grassland (e.g. alpine meadow, alpine steppe) and at least three pairs of comparative samples for each typical nature reserve (e.g. Qiangtang, Sanjiangyuan) to ensure that the main vegetation types and large reservations were represented in the analysis.

We identified all the pairs of comparative samples that met these conditions based on the distribution of alpine grassland and their distribution within and outside the nature reserves (Figure 1b). We identified 21 pairs (42 samples) of comparative samples of all types. There were eight pairs of samples in the Sanjiangyuan Nature Reserve, six pairs of samples in Qiangtang Nature Reserve, two pairs in Selincuo Nature Reserve and only one pair of samples in each of the other five nature reserves, namely, Taxkorgan Wild Animal Nature Re- 
serve, Mid-Kunlun Nature Reserve, Changshagongma Nature Reserve, Manzetang Nature Reserve and Zoige Wetland Nature Reserve, which cover only a small area each. No comparative sample met the design principle in the Altun Mountain Nature Reserve, Hoh Xil Nature Reserve or Yanchiwan Nature Reserve. The sample areas were mainly covered by alpine meadow (ten pairs), alpine steppe (eight pairs), alpine desert (two pairs) and wetland (one pair) (Table 2). The sampled areas of the internal and external nature reserves were 6.95 $\times 10^{4}$ and $7.84 \times 10^{4} \mathrm{~km}^{2}$, respectively. The area of samples within the nature reserves accounted for $10.98 \%$ of the total area of the nature reserves and $15.62 \%$ of the total area of alpine grassland within the nature reserves.

Table 2 Data for typical sample pairs

\begin{tabular}{|c|c|c|c|}
\hline Sample No. & Nature reserve & Vegetation type & $\begin{array}{l}\text { Number of effective pixels in inter- } \\
\text { nal/external samples* }\end{array}$ \\
\hline 1 & Taxkorgan & Alpine steppe & $87 / 102$ \\
\hline 2 & Mid-Kunlun Mountain & Alpine desert & $34 / 63$ \\
\hline 3 & Qiangtang & Alpine steppe & $54 / 71$ \\
\hline 4 & Qiangtang & Alpine desert & $62 / 66$ \\
\hline 5 & Qiangtang & Alpine steppe & $102 / 84$ \\
\hline 6 & Qiangtang & Alpine steppe & $80 / 88$ \\
\hline 7 & Qiangtang & Alpine steppe & $91 / 93$ \\
\hline 8 & Qiangtang & Alpine steppe & $86 / 97$ \\
\hline 9 & Selincuo & Alpine steppe & $51 / 79$ \\
\hline 10 & Selincuo & Alpine meadow & $77 / 147$ \\
\hline 11 & Sanjiangyuan & Alpine meadow & $70 / 95$ \\
\hline 12 & Sanjiangyuan & Alpine meadow & $132 / 98$ \\
\hline 13 & Sanjiangyuan & Alpine meadow & $148 / 95$ \\
\hline 14 & Sanjiangyuan & Alpine meadow & $115 / 106$ \\
\hline 15 & Changshagongma & Alpine meadow & $90 / 110$ \\
\hline 16 & Sanjiangyuan & Alpine meadow & $115 / 145$ \\
\hline 17 & Manzetang & Alpine meadow & $46 / 113$ \\
\hline 18 & Sanjiangyuan & Alpine meadow & $125 / 94$ \\
\hline 19 & Sanjiangyuan & Alpine meadow & $77 / 80$ \\
\hline 20 & Sanjiangyuan & Alpine steppe & $70 / 70$ \\
\hline 21 & Zoige & Wetland & $37 / 50$ \\
\hline
\end{tabular}

*For greater accuracy, all the NPP data in the internal and external representative sample areas only count the number of effective pixels of vegetation types. The effective pixels refer to complete pixels $\left(0.05^{\circ} \times 0.05^{\circ}\right)$ with alpine grassland vegetation, for which the yearly NPP value can be included in the source data.

We chose two indicators to characterize the differences in effectiveness of protection in the sample pairs: the protection amplitude $\left(P_{k}\right)$ and the protection amplitude ratio $\left(P_{r}\right)$. The protection amplitude $\left(P_{k}\right)$ is the variation in amplitude of the net increase or net decrease in the NPP of the internal zone of the sample minus that of the external zone of the sample per unit time and unit area; a positive value indicates an increase in the NPP and a negative 
value indicates a decrease in the NPP. The protection amplitude ratio $\left(P_{r}\right)$ is the ratio of the protection amplitude to the amplitude for a condition of no protection (the NPP of the external sample of the pair) per unit time and unit area. These two indicators are used to characterize a significant degree of protection effectiveness. The two calculation formulas are:

$$
\begin{gathered}
P_{k}=k_{p}-k_{n} \\
P_{r}=\frac{k_{p}-k_{n}}{\left|k_{n}\right|}
\end{gathered}
$$

where $k_{p}$ is the average amplitude of variation per unit time and unit area in the sample inside the nature reserve for the period before and after the reserve was created and $k_{n}$ is the average amplitude of variation per unit time and unit area in the sample outside the nature reserve for the period before and after the reserve was established.

\section{Results}

\subsection{Temporal and spatial characteristics of alpine grassland NPP in nature reserves}

Among the typical nature reserves, the vegetation type of Qiangtang, Hoh Xil and Taxkorgan nature reserves is mainly alpine steppe; the Sanjiangyuan, Changshagongma, Selincuo, Zoige and Manzetang nature reserves are mainly covered by alpine meadow and the MidKunlun nature reserve is mainly covered by alpine desert and alpine sparse vegetation. The vegetation types are approximately the same inside and outside the nature reserves (Figure 1a).

\subsubsection{Spatial distribution of NPP}

Between 1982 and 2009, the distribution of the average annual NPP in alpine grassland in each nature reserve and the surrounding zone gradually increased from the west (north) to the east (south) (Figure 2). This distribution is consistent with the regional spatial distribution of precipitation and temperature. The annual alpine grassland NPP of all the typical nature reserves is $87.47 \mathrm{gC} \mathrm{m}^{-2} \mathrm{yr}^{-1}$, the annual NPP of all the national nature reserves is 87.33 $\mathrm{gC} \mathrm{m}^{-2} \mathrm{yr}^{-1}$ and the annual NPP of all the provincial nature reserves is $93.95 \mathrm{gC} \mathrm{m}^{-2} \mathrm{yr}^{-1}$, whereas the annual NPP in the zone surrounding all the typical nature reserves is $157.86 \mathrm{gC}$ $\mathrm{m}^{-2} \mathrm{yr}^{-1}$ (Figure 2). Therefore the ecological environment in the nature reserves, especially the national nature reserves, is more fragile than in the surrounding regions.

Comparing the mean NPP of all types of alpine grassland in all typical nature reserves and in their surrounding zones with the mean NPP of alpine grassland in the Tibetan Plateau, we showed that the mean NPP of all types of alpine grassland in the zones surrounding the nature reserves was higher than that for the Tibetan Plateau. However, the mean NPP of alpine desert was the same in the zones surrounding the nature reserves and in the Tibetan Plateau, whereas the mean NPP of alpine desert and alpine sparse vegetation in the national nature reserves and the mean NPP of alpine meadows in provincial nature reserves was higher than that in the zones surrounding the nature reserves. The mean NPP of other type of alpine grasslands was lower than the average NPP of the Tibetan Plateau (Table 3). The ecological environment of the Mid-Kunlun Provincial Nature Reserve, which is mainly covered by alpine desert and alpine sparse vegetation, and the Manzetang Provincial Nature Reserve, 
which is mainly covered by alpine meadow, was better than that of other nature reserves during the research period (Figure 2 and Table 3 ).

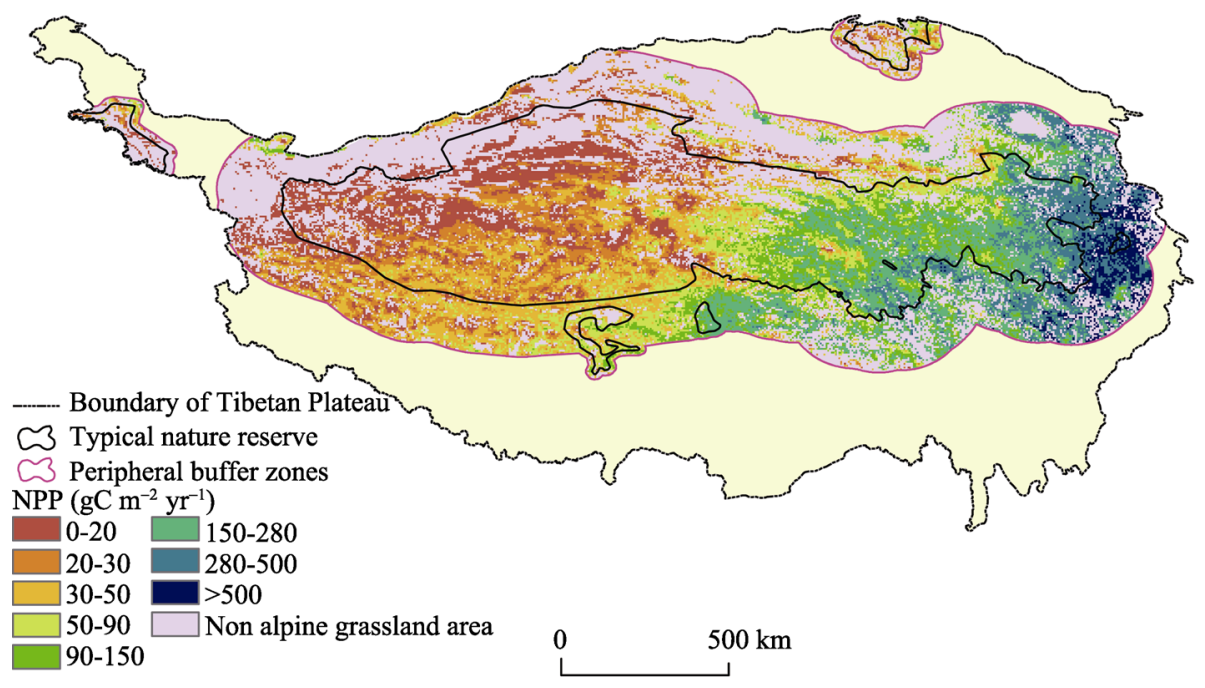

Figure 2 Distribution of NPP inside typical nature reserves and peripheral buffer zones of the Tibetan Plateau. Data are based on results of Zhang et al. (2014).

Table 3 Comparison of NPP of alpine grassland vegetation on the Tibetan Plateau $\left(\mathrm{gC} \mathrm{m}^{-2} \mathrm{yr}^{-1}\right)$

\begin{tabular}{lcccc}
\hline \multirow{2}{*}{ Vegetation type } & \multicolumn{2}{c}{ Representative nature reserve } & Surrounding area & $\begin{array}{c}\text { Tibetan Plateau } \\
\text { of nature reserve }\end{array}$ \\
\cline { 2 - 4 } (Zhang et al., 2014)
\end{tabular}

Note: Data are given as mean \pm SD values.

\subsubsection{Trends in NPP}

The annual NPP of alpine grassland in 11 typical nature reserves showed increasing trends of different degrees during the period 1982-2009 (Figure 3). The increasing trend observed for the Manzetang Nature Reserve is the most significant, with a value of about $1.54 \mathrm{gC} \mathrm{m}^{-2}$ $\mathrm{yr}^{-1}$, whereas that for the Taxkorgan Nature Reserve is not obvious and has a value of only $0.03 \mathrm{gC} \mathrm{m}^{-2} \mathrm{yr}^{-1}$. The rate of increase in the NPP for nature reserves mainly covered by alpine meadow and wetland is higher than that for nature reserves covered by alpine steppe and alpine desert, with the exception of the Selincuo Nature Reserve.

We divided the time period into two stages: before and after each nature reserve was established (note: the Yanchiwan Nature Reserve and the Altun Mountain Nature Reserve were established at about the time that this research started). Comparative analysis showed that the increasing trend in the NPP was higher after the Manzetang, Mid-Kunlun, Changshagongma and Zoige nature reserves were established than the trend before these nature 

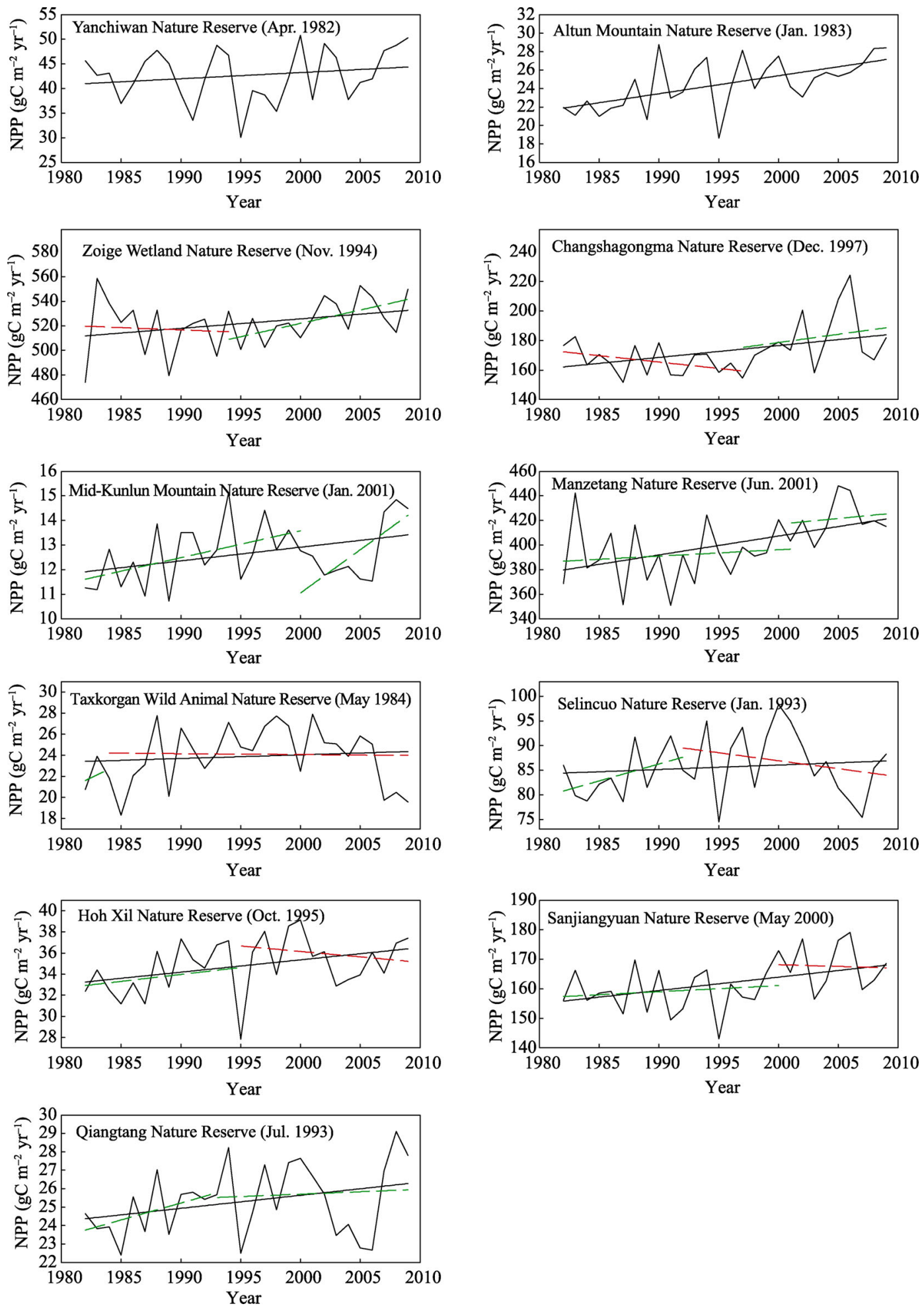

Figure 3 Changes in the NPP in natural reserves before and after their establishment. Red lines represent decreasing trends and green lines represent increasing trends 
reserves were established. The increasing trend in the NPP after the Qiangtang Nature Reserve was established was lower than the trend before it was established; however, there was a decreasing trend in the NPP for the other four nature reserves after they were established. Studies have shown that the alpine grassland NPP has been affected by the overall effects of precipitation and temperature over the past 30 years. There were three relatively large fluctuations and the NPP dipped in 1987, 1995 and 2003 (Zhang et al., 2014). Figure 3 shows that the NPP in most nature reserves also dipped at these times and the downward trend was most significant around 1995. Even in the same nature reserve, we cannot simply attribute changes in the NPP before and after the nature reserve was established to the effectiveness of protection. There will therefore be great uncertainty if we evaluate the effectiveness of protection in the nature reserves with respect to differences in the regional climate.

\subsection{Effectiveness of protection based on the large sample comparison method}

\subsubsection{Changes in the NPP inside and outside nature reserves}

The NPP is affected by both natural and human activities. Directly comparing changes in the NPP before and after a nature reserve is established cannot truly reflect its effectiveness of protection. After analyzing the spatio-temporal changes in the NPP trends for alpine grassland in typical nature reserves, we selected a total of 42 samples ( 21 pairs) to analyze the differences between the zones inside and outside the nature reserves before and after they were established.

The vegetation growth status in 21 sample pairs was obviously different as a result of the different types of land cover. Among the 21 pairs of samples, the lowest average annual NPP (12.23 $\mathrm{gC} \mathrm{m}^{-2} \mathrm{yr}^{-1}$ ) was seen in the external zone (a matched sample located in the peripheral buffer zone outside the nature reserve) of sample 2 (alpine desert in Mid-Kunlun Provincial Nature Reserve) between 1982 and 2009. The highest value (556.24 gC m $\mathrm{gr}^{-1}$ ) was seen in the external zone of sample 21 (wetland of Zoige Wetland National Nature Reserve). The annual average NPP was higher in the external zone than in the internal zone for eight pairs of samples; another eight pairs of samples had the opposite results and there was little difference between the internal and external zones for the remaining five pairs of samples.

As can be seen from the trend in annual NPP from 1982 to 2009, only five of the 42 samples showed a slightly decreasing trend in the NPP; the others all showed a trend of fluctuating increase. The increasing trend of the NPP in the internal sample was higher than that in the external sample in 12 pairs of samples (Figure 4).

\subsubsection{Changes in the NPP before and after the establishment of nature reserves}

We divided the time period into two stages: before and after each nature reserve was established. When the samples were selected, we assumed that the NPP outside each nature reserve was affected by both natural and human activities without protection, whereas the NPP inside each nature reserve was the result of protection. Furthermore, the climate in each pair of samples (inside and outside the nature reserve) was basically similar. Therefore a comparison of the internal and external zones of each sample pair can better illustrate the effectiveness of protection.

The trend in the NPP of the 21 pairs of samples can be divided into the following five types. 
(1) Trends before reserve establishment were of the same type, but those after establishment were of the opposite type

The trend was the same for the internal and external samples before the nature reserve
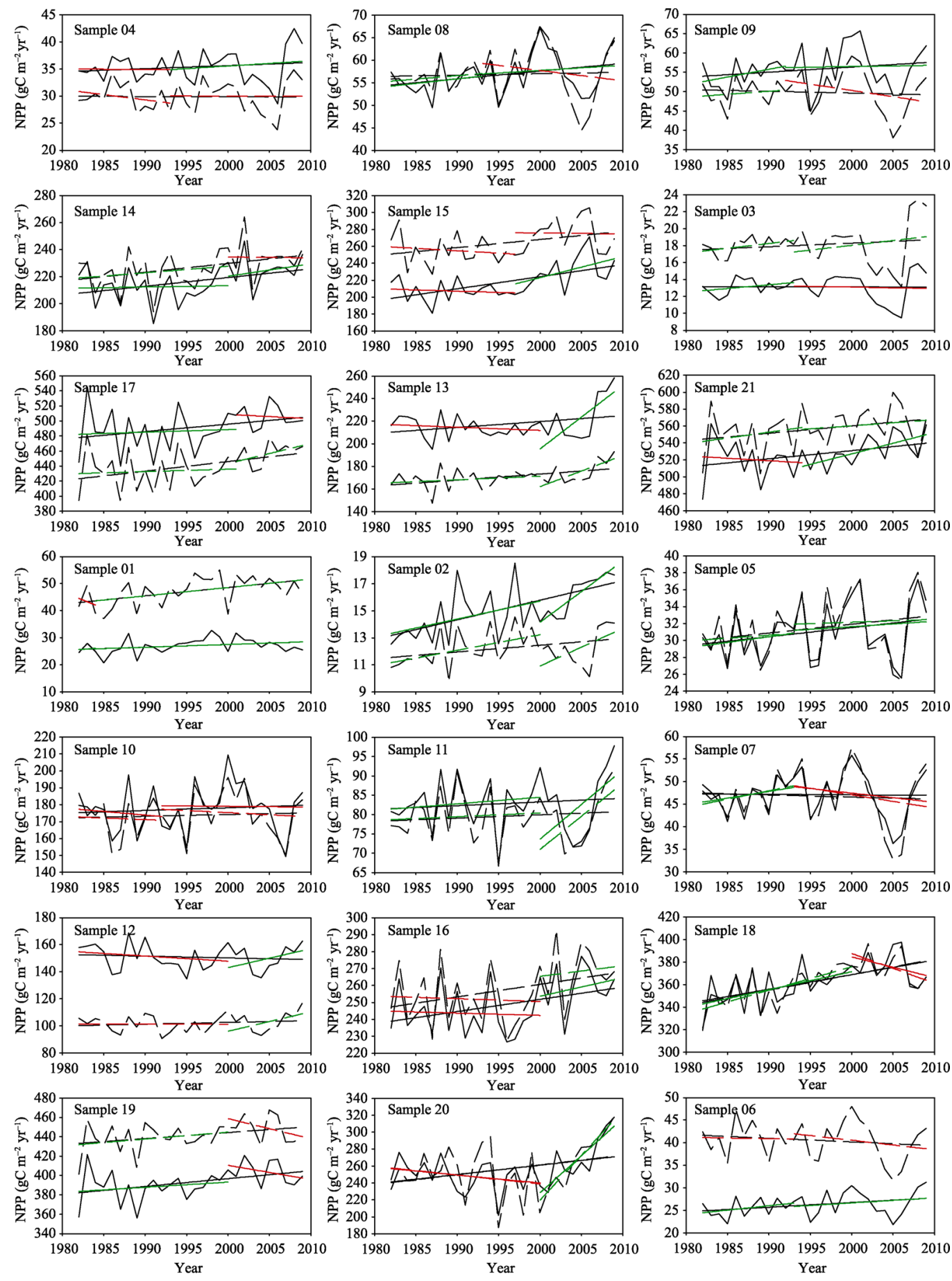

Figure 4 Changes in the NPP in sample pairs before and after the establishment of the natural reserves. Red lines represent decreasing trends and green lines represent increasing trends 
was established (the first stage), but one trend changed after the nature reserve was established (the second stage). In five pairs of samples of this type (samples 4, 8, 9, 14 and 15), the NPP of the internal sample showed an increasing trend in the second stage, whereas the NPP of the external sample showed a decreasing trend. This indicated that the protection effectiveness of these five pairs of samples was significant. Another two pairs of samples (samples 3 and 17) showed the opposite trend in the second stage compared with the first five pairs of samples, indicating that the protection effect was poor.

(2) Trends before reserve establishment were of opposite types, but those after establishment were of the same type

There was an increasing trend in the NPP in both samples after the nature reserve was established, but there was a difference before the nature reserve was established. In two sample pairs (13 and 21), the NPP showed a decreasing trend in the internal samples, but an increasing trend in the external samples in the first stage. These results proved that the protective effect in the internal samples resulted in a change in the NPP from a "decreasing trend" in the first stage to an "increasing trend" in the second stage compared with the environmental background before and after the nature reserve was established. The trend shown for sample 1, however, is the opposite of these two pairs of samples.

(3) Consistent trends

In four pairs of samples, the trend in the NPP was of the same type in both the internal and external samples in both stages (samples 2, 5, 10 and 11).

(4) Trends before reserve establishment were the opposite of trends after reserve establishment

There were six pairs of samples (samples 7, 12,16, 18, 19 and 20) for which the trend in NPP was the same in the internal and external samples for each stage, but different in the two stages.

(5) Trends were consistent, but opposite

The changing trend was consistent in the internal and external samples before and after the nature reserve was established, but the trend was opposite for the two samples-for example, in sample 6, there was an increasing trend in the NPP in the internal sample for both stages, but a decreasing trend in the external sample for both stages.

The differences in the trends between the internal and external zone samples for each stage and the effectiveness of protection inside the nature reserves can be discussed by comparing the protection amplitude $\left(P_{k}\right)$. Of the 21 sample pairs, the $P_{k}$ was positive in 15 pairs of samples and the $P_{k}$ of sample 21 was the highest at approximately 3.74. The $P_{k}$ value of the remaining six pairs of samples was negative; sample 17 had the lowest $P_{k}$ value of approximately -3.27 . The vegetative type of four of these six sample pairs was alpine steppe. This indicates that the protection effect of alpine steppe-type nature reserves was poor (Figure 4).

The protection amplitude ratio $\left(P_{r}\right)$ of five sample pairs (samples 10,13, 14, 15, and 21) was $>1$; of these sample pairs, sample 10 had the highest protecting amplitude ratio of approximately 9.17 . The vegetation types of these five pairs of samples were all alpine meadow. This indicated that the protection effectiveness of alpine meadow-type nature reserves is significant. Three pairs of samples (samples 1,3, and 17) had a protection amplitude ratio less than -1 ; of these sample pairs, sample 3 had the lowest $P_{r}$ value of approximately -105.5 . 
An effectiveness analysis of the changing trends in the NPP of types (3) to (5) revealed that the $P_{r}$ value of nine of these 11 pairs of samples was positive (only that of samples 5 and 20 were negative), indicating that the effectiveness of protection of these sample pairs was good (Table 4).

Table 4 Amplitude and amplitude ratio of the NPP in sample pairs before and after the establishment of nature reserves

\begin{tabular}{|c|c|c|c|c|c|c|c|c|}
\hline & ample area & & Analysis per & & & & & \\
\hline $\begin{array}{c}\text { Sample } \\
\text { No. }\end{array}$ & Sample pair & $\begin{array}{l}\text { Whole } \\
\text { period } \\
(1982- \\
2009) / \mathrm{k} \\
\end{array}$ & $\begin{array}{l}\text { First stage } \\
\text { (1982 to es- } \\
\text { tablishment) }\end{array}$ & $\begin{array}{l}\text { Second stage } \\
\text { (establishment } \\
\text { to 2009) }\end{array}$ & $\begin{array}{c}\text { Protection } \\
\text { amplitude } \\
/ \mathrm{P}_{\mathrm{k}}\end{array}$ & $\begin{array}{c}\text { Protection } \\
\text { amplitude } \\
\text { ratio/ } / \mathrm{P}_{\mathrm{r}}\end{array}$ & Nature reserve & $\begin{array}{l}\text { Vegetation } \\
\text { type }\end{array}$ \\
\hline 1 & Inside reserve & 0.10 & 0.24 & 0.10 & $-1,66$ & -1.09 & Taxkorgan & Alpine \\
\hline 1 & Outside reserve & 0.31 & -1.22 & 0.31 & -1.00 & -1.09 & 1 axkण ö & steppe \\
\hline 2 & Inside reserve & 0.14 & 0.13 & 0.45 & 016 & 007 & Mid_Kunlun & Alpine \\
\hline 2 & Outside reserve & 0.05 & 0.11 & 0.28 & 0.10 & 0.91 & MIId-K umIUn & desert \\
\hline 4 & Inside reserve & 0.06 & -0.01 & 0.10 & -000 & -0.47 & & Alpine \\
\hline 4 & Outside reserve & 0 & -0.19 & -0.003 & -0.09 & -0.47 & & desert \\
\hline 3 & Inside reserve & 0 & 0.09 & -0.02 & -011 & -10550 & & \\
\hline$J$ & Outside reserve & 0.04 & 0.11 & 0.11 & 0.11 & 100.00 & & \\
\hline 5 & Inside reserve & 0.11 & 0.13 & 0.06 & -0.03 & -0.78 & & \\
\hline$J$ & Outside reserve & 0.10 & 0.07 & 0.03 & $0.0 \mathrm{~J}$ & & Oianotang & \\
\hline 6 & Inside reserve & 0.10 & 0.20 & 0.11 & 010 & 054 & Q Tangtang & Alpine \\
\hline 0 & Outside reserve & -0.08 & -0.03 & -0.21 & 0.10 & 0.34 & & steppe \\
\hline 7 & Inside reserve & -0.01 & 0.30 & -0.20 & 0.16 & 024 & & \\
\hline 1 & Outside reserve & -0.05 & 0.37 & -0.29 & & & & \\
\hline 8 & Inside reserve & 0.17 & 0.20 & 0.11 & 0.29 & 077 & & \\
\hline & Outside reserve & 0.03 & 0.15 & -0.23 & 0.29 & & & \\
\hline 9 & Inside reserve & 0.13 & 0.40 & 0.03 & 011 & 023 & & Alpine \\
\hline 9 & Outside reserve & -0.05 & 0.15 & -0.32 & 0.11 & 0.25 & Solinou & steppe \\
\hline 10 & Inside reserve & 0.16 & -0.42 & -0.05 & 0.42 & 917 & Notinte & Alpine \\
\hline 10 & Outside reserve & 0.10 & -0.20 & -0.25 & 0.42 & 9.17 & & meadow \\
\hline 20 & Inside reserve & 1.10 & -0.94 & 8.76 & -194 & -017 & & Alpine \\
\hline 20 & Outside reserve & 1.16 & -1.05 & 10.60 & ד & 0.17 & & steppe \\
\hline 11 & Inside reserve & 0.10 & 0.17 & 1.79 & 001 & 001 & & \\
\hline 11 & Outside reserve & 0.08 & 0.10 & 1.71 & 0.01 & 0.01 & & \\
\hline 12 & Inside reserve & -0.13 & -0.38 & 1.40 & 033 & 023 & & \\
\hline 12 & Outside reserve & 0.13 & -0.01 & 1.44 & 0.53 & 0.25 & & \\
\hline 13 & Inside reserve & 0.52 & -0.29 & 5.64 & 3.50 & 1.44 & & \\
\hline & Outside reserve & 0.54 & 0.32 & 2.74 & & & Sanjiangyuan & \\
\hline 14 & Inside reserve & 0.64 & 0.09 & 0.92 & 135 & 2.57 & & Alpine \\
\hline 14 & Outside reserve & 0.65 & 0.48 & -0.05 & 1.35 & 2.51 & & meadow \\
\hline 16 & Inside reserve & 0.72 & -0.13 & 1.09 & 043 & 0.54 & & \\
\hline 10 & Outside reserve & 0.74 & -0.17 & 0.63 & 0.43 & 0.04 & & \\
\hline 18 & Inside reserve & 1.29 & 1.59 & -1.83 & 129 & 027 & & \\
\hline 10 & Outside reserve & 1.37 & 2.08 & -2.63 & & & & \\
\hline 19 & Inside reserve & 0.81 & 0.53 & -1.47 & 078 & 028 & & \\
\hline & Outside reserve & 0.62 & 0.72 & -2.07 & & & & \\
\hline 15 & Inside reserve & 1.43 & -0.29 & 2.49 & 231 & 501 & Chang- & Alpine \\
\hline 15 & Outside reserve & 0.96 & -0.57 & -0.11 & 2.31 & 0.01 & shagongma & meadow \\
\hline 17 & Inside reserve & 0.99 & 0.34 & -0.58 & -327 & -139 & Manzetano & Alpine \\
\hline & Outside reserve & 1.27 & 0.32 & 2.68 & 0. & 1.59 & Mranzetang & meadow \\
\hline 21 & Inside reserve & 0.97 & -0.58 & 2.51 & 374 & 570 & Zoige & Wetland \\
\hline 21 & Outside reserve & 0.87 & 1.37 & 0.72 & 3.7 & 5.70 & 201 ige & veriana \\
\hline
\end{tabular}


When considering the trends in the NPP, the $P_{k}$ and the $P_{r}$ ratio together, we found that there were 16 pairs of samples with good protection effectiveness (15 pairs of samples with a positive $P_{k}$ value and sample 4, for which the changing trend of NPP became good). Considering the different types of vegetation, the effectiveness of protection of alpine meadowtype samples was good and that of alpine steppe-type samples was poor. The $P_{k}$ value observed for more than $76 \%$ of the samples inside nature reserves and more than $82 \%$ of the samples inside national nature reserves was higher than that of samples outside nature reserves after the nature reserves has been established. In view of the nature reserves in which the sample pairs were located, it became clear that there was more effectiveness of ecological protection in most areas of the Mid-Kunlun, Changshagongma, Zoige, Selincuo, Sanjiangyuan and Qiangtang nature reserves, whereas the protection effectiveness in the south-eastern part of Manzetang Nature Reserve and the northern part of Taxkorgan Wild Animal Nature Reserve was not significant. Considering the administrative regions in which the sample pairs were located, the areas in which the protection effectiveness of the nature reserves was not significant were mainly concentrated in Taxkorgan County in Xinjiang Autonomous Region (sample 1), the Ali area in Tibet Autonomous Region (samples 3 and 5), Aba County in Sichuan Province (sample 17), Xinghai County and Tongde County in Qinghai Province (sample 20).

\section{Discussion and conclusions}

\subsection{Discussion}

Five sample pairs (samples 1, 3, 5, 17 and 20) did not show any obvious effectiveness of protection. This may be related to factors such as increased grazing pressures and a worsening climate over the same period. Sample 1 was located in the northwest-north-northeast of the Taxkorgan Wild Animal Nature Reserve, which accounts for $62.3 \%$ of the area of Taxkorgan County. According to the Xinjiang Statistical Yearbook (Edited by Statistic Bureau of Xinjiang Urgur Autonomous Region) published between 1989 and 2013, the number of livestock in this county has increased continuously since 1988; this may result in the grassland becoming overloaded, leading to serious grassland degradation (Yue et al., 2011). Samples 3 and 5 are located in the central-west part of the Qiangtang Nature Reserve in the Ali region. Current research indicates that the climate in the northwest of Tibet has become warmer and dryer over the period from 1970 to 2010 (Zhang et al., 2013a), leading to intensified drought conditions, causing a continuous degradation of grassland (Yang, 2002). The growth rate of livestock reached $40.00 \%, 12.14 \%$ and $8.19 \%$, respectively, in Gaize, Geji and Ritu counties during the period 1985-2009, in which samples 3 and 5 were located; the overloading rate in Gaize and Geji county reached $11.04 \%$ and $23.10 \%$, respectively, in 2010 (Chang et al., 2012). Sample 17 was located in the southeastern part of Manzetang Nature Reserve in the Aba region of Sichuan Province; here, human disturbance is frequent and the ecology and environment in this region have worsened and the effectiveness of protection is not obvious (Dai and Min, 2009). Sample 20 is located in the northeast of the Sanjiangyuan National Nature Reserve; this region did not belong to the core area of the nature reserve at one time, so it lacked substantial protection. The Ecological Protection and Con- 
struction Project of Sanjiangyuan came into effect in 2005. People have begun to return grazing land to grassland and the effectiveness of protection has begun to reappear in this region (Shao et al., 2012; Liu et al., 2013; Figure 4). The Tibetan-inhabited regions are usually located in the areas adjacent to nature reserves; some important economic development regions, such as county towns, are also distributed within nature reserves. This also means that grazing activity has affected the nature reserves in different ways and has affected their function (Glindermann et al., 2009; Chen et al., 2014).

\subsection{Conclusions}

Based on the long time series of the NPP data, this study analyzed changes in the NPP inside and outside 11 typical nature reserves and used the LSCM to evaluate effectiveness of protection of the selected 21 samples pairs on the Tibetan Plateau before and after their establishment by two indicators: the protection variation amplitude and the protection variation amplitude ratio.

From 1982 to 2009, the ecological and environmental conditions of most nature reserves were more fragile than those of their surrounding areas and also lower than the average values for the Tibetan Plateau. The exceptions were the Mid-Kunlung Nature Reserve, which is mainly covered by alpine desert and alpine sparse vegetation, and the Manzetang Nature Reserve, which is mainly covered by alpine meadow; both these reserves had good ecological and environmental conditions.

The annual average NPP of 11 typical nature reserves showed increasing trends of varying degrees over the research periods. Among these, the increasing trend in the Manzetang Nature Reserve was the most significant and the increasing trend in the Taxkorgan Wild Animal Nature Reserve was the weakest. The rate of increase in the NPP in the nature reserves mainly covered by alpine meadow and wetland was higher than that of nature reserves mainly covered by alpine steppe and alpine desert, with the exception of the Selincuo Nature Reserve. Differences in the regional climate is the main uncertainty to evaluate the effectiveness of protection in the nature reserves by NPP data.

From a comparative analysis of the samples, the following deductions can be made.

(1) After the nature reserves were established, the rate of increase in the NPP in more than $76 \%$ of samples inside nature reserves and more than $82 \%$ of samples inside national nature reserves was higher than that of the corresponding samples outside nature reserves, demonstrating the effectiveness of protection of the nature reserves.

(2) The nature reserves with the most obvious effectiveness of protection were MidKunlun, Changshagongma, Zoige and Selincuo. Most parts of the Sanjiangyuan and Qiangtang nature reserves showed an obvious effectiveness of protection. However, the effectiveness of protection of the Manzetang and Taxkorgan Wild Animal nature reserves was not significant.

(3) The effectiveness of protection of the nature reserves covered with alpine meadow was significant, whereas the effectiveness of protection of nature reserves covered with alpine steppe was poor.

This research showed that we can analyze scientific data obtained by remote sensing to obtain evaluation indexes to compare large samples. The protection variation amplitude and 
protection variation amplitude ratio enabled us to evaluate the effectiveness of human activities, such as ecological protection and the establishment of nature reserves, and the degree of influence of natural factors, such as climate change. Careful design of the samples used, to ensure comparability between the samples, is crucial to the success of this LSCM.

\section{Acknowledgments}

We thank Prof. ZHANG Xianzhou, Dr ZHOU Caiping, Mr ZHAO Zhilong and Dr TAO Jian from Institute of Geographic Sciences and Natural Resources Research, Chinese Academy of Sciences for providing county statistical data of liverstock in Tibet Autonomous Region and Qinghai Province, and also thank the anonymous reviewers for their constructive comments on the original manuscript.

\section{References}

Andam K S, Ferraro P J, Pfaff A et al., 2008. Measuring the effectiveness of protected area networks in reducing deforestation. Proceedings of the National Academy of Sciences USA, 105(42): 16089-16094.

Bruner A G, Gullison R E, Rice R E et al., 2001. Effectiveness of parks in protecting tropical biodiversity. Science, 291: 125-128.

Caro T, Gardner T A, Stoner C et al., 2009. Assessing the effectiveness of protected areas: Paradoxes call for pluralism in evaluating conservation performance. Diversity and Distributions, 15: 178-182.

Chang H Q, Xu W Y, Yuan J et al., 2012. Current situation of grassland resources and grazing capacity in Ali, Tibet. Pratacultural Science, 29(11): 1660-1664. (in Chinese)

Chen B X, Zhang X Z, Tao J et al., 2014. The impact of climate change and anthropogenic activities on alpine grassland over the Qinghai-Tibet Plateau. Agricultural and Forest Meteorology, 189: 11-18.

Chen J K, 2012. Insights into the history of conservation of natural wetlands in China. Chinese Science Bulletin, 57(4): 205-206. (in Chinese)

Chen J K, Lei G C, Wang X L, 2010. Analysis of Ten Effective Management Case in the Middle and Lower Reaches of the Yangtze River. Shanghai: Fudan University Press. (in Chinese)

Crabtree R, Potter C, Mullen R et al., 2009. A modeling and spatio-temporal analysis framework for monitoring environmental change using NPP as an ecosystem indicator. Remote Sensing of Environment, 113(7): 1486-1496.

Cui G F, 2004. Special research fields and hot spots in science of nature reserves. Journal of Beijing Forestry University, 26(6): 102-105. (in Chinese)

Curran L M, Trigg S N, McDonald A, 2004. Lowland forest loss in protected areas of Indonesian Borneo. Science, 303: $1000-1003$.

Dai L D, Min H X, 2009. Countermeasures on the sustainable development of Manzetang wetland nature reserve in Sichuan. Sichuan Forestry Exploration and Design, (4): 39-42. (in Chinese)

Deng M L, Tian K, Duan Z L et al., 2010. The changes of landscape at Zoige Plateau wetland reserve in Sichuan, China. Journal of Mountain Science, 28(2): 240-246. (in Chinese)

Department of Environment Protection of Qinghai Province, Bureau of Quality and Technology Supervision of Qinghai Province (DEPQP), 2015. Local Standard of Qinghai Province-Technical Specification for Evaluation on Ecological Effect of Ecological Protection and Construction of Three-Rivers Nature Reserve (DB63/T1342-2015).

Ewers R M, Rodrigues A S L, 2008. Estimates of reserve effectiveness are confounded by leakage. Trends in Ecology \& Evolution, 23(3): 113-116.

Glindermann T, Wang C, Tas B M et al., 2009. Impact of grazing intensity on herbage intake, composition, and 
digestibility and on live weight gain of sheep on the Inner Mongolian steppe. Livestock Science, 124: $142-147$.

Leverington F, Costa K L, Pavese H et al., 2010. A global analysis of protected area management effectiveness. Environmental Management, 46: 685-698.

Liu J, Li S, Ouyang Z et al., 2008. Ecological and socioeconomic effects of China's policies for ecosystem services. Proceedings of the National Academy of Sciences, 105: 9477-9482.

Liu J G, Linderman M, Ouyang Z Y et al., 2001. Ecological degradation in protected areas: The case of Wolong Nature Reserve for Giant Pandas. Science, 292: 98-101.

Liu J Y, Shao Q Q, Fan J W, 2013. Ecological construction achievements assessment and its revelation of ecological project in Three Rivers Headwaters Region. Chinese Journal of Nature, 35(1): 40-46. (in Chinese)

Ma J Z, 1992. Science of Nature Conservation. Harbin: Northeast Forestry University Press. (in Chinese)

Mas J, 2005. Assessing protected area effectiveness using surrounding (buffer) areas environmentally similar to the target area. Environmental Monitoring and Assessment, 105: 69-80.

Melillo J M, Mcguire A D, Kicklighter D W et al., 1993. Global climate-change and terrestrial net primary production. Nature, 363(6426): 234-240.

Mittermeier R A, Turner W R, Larsen F W et al., 2011. Global Biodiversity Conservation: the Critical Role of Hotspots. In: Zachos F E, Habel J C. Biodiversity Hotspots. Berlin \& Heidelberg: Springer, 3-22.

Naidoo R, Balmford A, Ferraro P J et al., 2006. Integrating economic costs into conservation planning. Trends in Ecology \& Evolution, 21: 681-687.

Nan W Y, 2013. On the unification of Qinghai-Tibet High Plateau nature and ecology projection. Tibetan Studies, (4): 44-51. (in Chinese)

Naughton-Treves L, Holland M, Brandon K, 2005. The role of protected areas in conserving biodiversity and sustaining local livelihoods. Annual Review of Environment and Resources, 30: 219-252.

Potter C S, Randerson J T, Field C B et al., 1993. Terrestrial ecosystem production: A process model-based on global satellite and surface data. Global Biogeochemical Cycles, 7(4): 811-841.

Quan J, Ouyang Z Y, Xu W H et al., 2009. Management effectiveness of China nature reserves: Status quo assessment and counter measures. Chinese Journal of Applied Ecology, 20(7): 1739-1746. (in Chinese)

Radeloff V C, Stewart S I, Hawbaker T J, 2010. Housing growth in and near United States protected areas limits their conservation value. Proceedings of the National Academy of Sciences, 107(2): 940-945.

Running S W, Nemani R R, Heinsch F A et al., 2004. A continuous satellite-derived measure of global terrestrial primary production. Bioscience, 54(6): 547-560.

Shao Q Q, Fan J W et al., 2012. Integrated Monitoring and Assessment of Ecosystem in the Source Regions of Three Rivers, China. Beijing: Science Press. (in Chinese)

Shvidenko A Z, Schepashchenko D G, Vaganov E A et al., 2008. Net primary production of forest ecosystems of Russia: A new estimate. Doklady Earth Sciences, 421(2): 1009-1012.

Stoner C, Caro T, Mduma S et al., 2007. Assessment of effectiveness of protection strategies in Tanzania based on a decade of survey data for large herbivores. Conservation Biology, 21: 635-646.

Sun H L, Zheng D, Yao T D et al., 2012. Protection and construction of the national ecological security shelter zone on Tibetan Plateau. Journal of Geographical Sciences, 67(1): 3-12. (in Chinese)

Underwood F M, 2012. A framework for adapting survey design through time for wildlife population assessment. Environmental and Ecological Statistics, 19: 413-436.

Victoria C J, Cheng M S, Chen X W, 2002. The development of Landscape Analysis of Wetland Function (LAWF): A GIS-based wetland functional assessment tool. Proceedings of the Water Environment Federation, Watershed, 418-424.

Wang W, Pechacek P, Zhang M et al., 2013. Effectiveness of nature reserve system for conserving tropical forests: A statistical evaluation of Hainan Island, China. PLoS ONE, 8(2): e57561.

Wang X P, Cui G F, 2003. Nature Reserve Construction and Management. Beijing: Chemical Industry Press. (in Chinese) 
Yan Y Y, Deng J, Zhang Z Q et al., 2014. Research progress in the protection efficacy evaluation of wildlife nature reserves. Chinese Journal of Ecology, 33(4): 1128-1134. (in Chinese)

Yan Y Y, Yang D D, Deng J et al., 2015. Construction of an indicator system for evaluating the protection efficacy of national nature reserves in China: A case study on terrestrial vertebrates (excluding migratory birds). Chinese Journal of Applied Ecology, 26(5): 1571-1578. (in Chinese)

Yang R R, 2002. Present situation of grassland degeneration and prevention measure in Ali Region, Xizang. Grassland of China, 24(1): 62-68. (in Chinese)

Yue P C, Dai J, Li D L et al., 2011. Major issues and countermeasure in the husbandry evelopment in Tashikuergan County. Grass-Feeding Livestock, (4): 21-23. (in Chinese)

Zhang H Z, Lu H Y, Hong J C et al., 2013a. Climate change and its effect on steppe animal husbandry in Northwest Tibet. Arid Zone Research, 30(2): 308-314. (in Chinese)

Zhang R Z, Li B Y, Zhang H X et al., 2012. Regional System of Natural Reserves in China. Beijing: China Environmental Science Press. (in Chinese)

Zhang W, 2007. Research of land use/cover classification and carbon stocks: A case study on Tibetan Plateau [D]. Beijing: Graduate University of Chinese Academy of Sciences. (in Chinese)

Zhang Y L, Li B Y, Zheng D, 2002. A discussion on the boundary and area of the Tibetan Plateau in China. Geographical Research, 21(1): 1-8. (in Chinese)

Zhang Y L, Qi W, Zhou C P et al., 2014. Spatial and temporal variability in the net primary production of alpine grassland on the Tibetan Plateau since 1982. Journal of Geographical Sciences, 24(2): 269-287.

Zhang Y L, Wang Z F, Wang X H et al., 2013b. Land cover changes in the key regions and self reflection on ecological construction of the Tibetan Plateau. Chinese Journal of Nature, 35(3): 187-192. (in Chinese)

Zhang Y L, Wu X, Qi W et al., 2015. Characteristics and protection effects of the nature reserves in Tibetan Plateau, China. Resources Science, 37(7): 1455-1464. (in Chinese)

Zheng Y M, Zhang H Y, Niu Z G et al., 2012. Protection efficacy of national wetland reserves in China. Chinese Science Bulletin, 57(4): 207-230. (in Chinese)

Zheng Y W, Xue D Y, Zhang G S, 1994. Study on ecological evaluation criteria and standards for nature reserves in China. Rural Eco-Environment, 10(3): 22-25. (in Chinese) 